\title{
O NOVO TITULAR, PROFESSOR FÁBIO NUSDEO, PROFERE SEU DISCURSO DE POSSE
}

Minhas primeiras palavras serão - como não poderiam deixar de ser de homenagem e de profunda reverência a estas Arcadas. Para todos nós elas representam algo de sacro, de permanente, de transcendental: o nicho onde se aninha o nosso espírito.

As palavras seguintes, como também não poderia deixar de ocorrer, são de agradecimento. E aí elas se estiolam pois, por certo, não conseguirão traduzir, nem palidamente, os sentimentos de quem as tenta pronunciar. Gratidão à minha família de origem que me deu as condições afetivas, psicológicas e também materiais para me lançar à empreitada. Gratidão especial à amada esposa que aliás conheci aqui nas Arcadas. Dela provém compreensão e inspiração sem limites. Aos queridos filhos, genro e nora, todos formados pelas mesmas Arcadas. Eles representaram estímulo adicional ao pai, aqui sob as vestes do professor. Amigos, parentes, companheiros de trabalho. A todos talvez tenha deixado de dar aquelas horas preciosas de convivio que a vida acadêmica sói roubar.

Para com o Professor José Ignácio Botelho de Mesquita torna-se duplamente dificil encontrar palavras que adequadamente expressem os sentimentos que nos unem. Na sua oração - tão primorosa, quão generosa afloraram mais os veios de uma amizade, anterior mesmo aos albores das nossas existências, porque vem de ambas as famílias vizinhas na velha e pacata Avenida Angélica da década de 30, ainda não pontilhada por um único arranha-céu sequer. Lá iniciou-se o nosso convívio, o qual continuou no ginásio, no colégio e na Faculdade, sempre contemporâneos e, sobretudo, amigos.

No momento em que S. Exa. com a fidalguia e a amizade habituais me abre as portas do último adro destas Arcadas para, com os ouropéis das pompas e alguma circunstância, como diria Sir Edward Elgar, receber-me juntamente com outros queridos colegas, ora titulares, parece adequado e mesmo natural indagar-se quanto ao sentido desta solenidade, parte integrante das mais vetustas e caras tradições da Casa. 
Uma impressão de momento ou uma aparência superficial the dariam o caráter puro e simples de uma chegada, de um término, de uma possível coroação de esforços, se quiserem.

No entanto, uma consideração mais meditada e mais profunda revelará, por certo, o seu sentido essencial, a obnubilar aquele primeiro, uma vez que, ao depois da chegada dá-se invariavelmente a largada, e, ao possível esforço coroado, deve suceder o esforço aplicado daí por diante na construção de algo. Aqui, portanto - e mais uma vez - não se trata do vir, mas sim do porvir.

$\mathrm{O}$ acesso à posição de titular deu-se dentro dos princípios da estrita legalidade o que o legitima pela origem. Mas a legitimidade desse acesso somente ganhará corpo e plenitude pela cabal assunção do novo status, dele fazendo uma sede e uma base para continuadas iniciativas de construção e de realização.

Com efeito, esta solenidade, certamente memorável para os ora recepcionados pela augusta Congregação, não deixa de guardar alguma semelhança com os austeros rituais com que nas primitivas tribos se conferiam aos novos guerreiros as armas, a serem brandidas na defesa do grupo. Traços também nela poderão se vislumbrar dos vetustos cerimoniais de unção daqueles que eram destinados a alguns ministérios de índole sacro-religiosa.

Muito mais, pois, do que de coroação, trata-se de investidura. E investidura implica missão. Ou melhor, impõe-na. Inescapavelmente. Missão, a não se exaurir na mera prática ou exercício de uma tarefa, pois transcende-a, por entranhar o seu direcionamento, imprimindo-lhe marca inconfundivel. Da mesma forma que o modesto sino do prisco Mosteiro, lépido e trepidante no nosso páteo, não se cinge a conclamar os alunos à recepção do ensino para, após, chamá-los de volta à efusão do convívio. Para além dessa tarefa primeira, alçou-se ele, pelo natural processo da simbologia humana, à condição de sentinela da liberdade no território de São Francisco; de toque de alerta a despertar o espírito de todos aqueles que nas Arcadas vivem ou viveram um dia.

Por tudo isso, senhores, senhoras, é o momento de o novo titular dizer, em rápidas palavras, a que veio; como encara e como se prepara para a sua missão. E missão é, ademais de investidura, compromisso.

Ao longo de toda a minha carreira, desde o Doutorado até a Titularidade, galgando os seus vários degraus então eram seis - impressionou-me 
crescentemente o quão caótico e pouco controlável se apresenta o processo decisório quanto ao emprego e o destino dos bens com que conta o homem para 0 atendimento de suas necessidades, não apenas as estritamente materiais, mas de toda ordem: as culturais, as afetivas, as espirituais, porque elas na sua multifária variedade se mesclam e se imbricam inextricavelmente.

O processo decisório levado a efeito no mercado, aparentemente fluido e escorreito, está sujeito a falhas decorrentes de seus pontos de inoperacionalidade. Transposto para o campo puramente institucional, outras falhas e vulnerabilidades se somam às primeiras. Os objetivos conflitantes e as pressões decorrentes dos interesses grupais fazem com que as leis, mormente as destinadas a regrar o processo econômico, não se gestem nos templa serena de que falava Lucrécio, mas sim no embate errático de forças indisciplinadas e indomadas.

Se a guerra nada mais vem a ser do que a continuação da diplomacia, agora com o emprego de meios violentos, na clássica colocação de Clausewitz, a feitura das leis e a tomada de decisões, em órgãos político-administrativos em todos os escalões, reproduzem, as mais das vezes, o fragor da batalha que antes se processava a nível de mercado.

Reconduzir todas essas decisões para o terreno puramente privatístico ou centralizá-las, de vez, no Poder Público, parece um dilema pueril quando não frívolo, pois a experiência histórica parece evidenciar, nos povos livres, um movimento pendular ora num sentido ora noutro, sem atingir, porém, os seus extremos. E ninguém tem o segredo ou a chave dessa evolução oscilatória. Da mesma forma que ninguém possui a autoridade - ética, moral, religiosa ou política para dizer em que posição deveria imobilizar-se o pêndulo. É a sociedade, cada sociedade, ao longo de sua trajetória histórica, quem fará as suas escolhas, impulsionando-o ao sabor de conviç̧ões que se lhe afigurem corretas a cada momento.

No fundo, tais conviç̧ões não passam de opções políticas e como o Direito é, no dizer de Carnelutti, o primeiro, o grande instrumento da política, cumpre-lhe desenvolver-se e aprestar-se, ao longo das linhas da Justiça para ensejar um sadio processo decisório qualquer que seja o seu âmbito - a fím de produzirem-se opções autênticas e expressivas, no sentido de expressarem com a 
possível fidelidade as tendências da sociedade, manifestadas com liberdade, sim, mas sem menoscabo à sua racionalidade e proficiência técnica.

Na visão de Max Weber a evolução da norma jurídica quanto a esse requisito, acompanha a própria transmutação dos sistemas econômicos. Da racionalidade puramente formal do liberalismo, tendeu-se gradualmente a uma racionalidade material - o materializierun - para chegar-se mais recentemente a um terceiro tipo: o da racionalidade procedimental o prozedurializierung - de que falam Teubner e Joergen na Alemanha, Andrini na Itália e Miaille na França, entre outros, além de vários estudiosos brasileiros, desta nossa Casa, como os eminentes professores Sampaio Ferraz, Grau e Oliveira Faria.

É o caminho da chamada auto-regulação, como antidoto natural contra a pura desregulação liberal, de um lado, e contra a centralizadora superregulação estatal de outro.

É na definição topográfica - se me permitem - desse caminho, no seu balizamento, na exploração, ainda quando tentativa, dessa via que a nova disciplina sob os meus cuidados - o Direito Econômico Aplicado - deverá primordialmente concentrar seus esforços e suas pesquisas nos próximos anos, sem negligenciar, é claro, os grandes tópicos da tutela da concorrência do consumidor, do meio ambiente e da parametrização legal de certas atividades específicas.

Por isso, Eminente Professor José Ignácio Botelho de Mesquita, a posição de Vossa Excelência, nesta noite, abrindo-me as portas da Congregação com a sua fidalguia, elegância, é, além de tudo, emblemática, porque representa num certo sentido, o enxerto de duas vergônteas entumecidas pela seiva promissora que carregam: uma oriunda do sólido sub-tronco do Direito Processual e a outra emergindo do talvez ainda tenro ramo - por ser mais recente - do Direito Econômico. Da junção de ambas, como disse, é lícito esperar-se ótimos frutos, frutos que não serão para nós mas, esperamos, possam ser colhidos pela sociedade brasileira na sua busca incessante - e até agora em boa parte frustrada - da Justiça e do Bem-Estar.

Mas se tal missão afigura-se dificultosa e de incertos resultados pelas limitações de quem a ela se propõe, perante tão escolhida Assemblẻia, será, na realidade, fácil e prazerosamente exercida quando se sabe estar inserida inteiramente na linha de preocupações e de pesquisa do eminente Professor Eros 
Roberto Grau, o titular da outra disciplina de Direito Econômico de quem continuarei, por certo, a receber a orientação, o estímulo e, principalmente, a amizade que ele nunca deixou me faltassem. Juntos e com o precioso concurso do ilustre Professor Doutor José Tadeu De Chiara poderemos, creio, almejar a condução do Direito Econômico pesquisado e ensinado nesta Faculdade ao progresso e à evolução consentâneos com os reclamos da sociedade brasileira mas sintonizados, porém, com o ensinamento vindo de além-fronteiras. Atentos sempre às exigências atuais da interdisciplinariedade que aqui vem se implantando de maneira firme e decidida com o apoio descortinado da douta Congregação e do eminente Senhor Diretor. Haja visto o recém-inaugurado Curso de Direito do Consumidor a envolver nada menos do que cinco departamento da Casa.

Ressalte-se, aliás, neste passo, a atuação e o decidido empenho do Diretor, na reorganização curricular do ensino ministrado nesta Casa, que envolveu, sempre com o apoio de Sua Excelência, a criação de novas disciplinas, ora preenchidas. Mas, tudo isso - Senhoras, Senhores insere-se no quadro maior da liberdade e da dignidade humana, cuja defesa tem sido o apanágio das Arcadas na sua luta pelo Direito, luta incessante, tendente a fazế-lo coincidir com o ideal de Justiça. Luta que apenas aflora nos embates dos pretórios, mas que o leva a firmarse por todas as partes e em todas circunstâncias, pois ela desenrola-se ao longo do tempo infinito, tem como palco a vida, como protagonistas a humanidade, por espectador supremo, Deus. 